and to develop a variation of the seismic method that can be used in deep water. A start has been made with this work, and when conditions again allow experiments at sea, there is little doubt that rapid progress will be made. The problems to be studied are of great importance for geology. The mapping of a section of the mid-Atlantic Ridge, for example, together with determinations of the velocities of elastic waves in it, could not fail to yield results of great interest. We know already that it includes features which are on a scale comparable with the Himalayas, and such a survey would indicate whether these mountains were a folded range that had never been exposed to denudation, a sunken land mass, or a system of submarine volcanoes. The major rival geological theories, such as the permanence of ocean basins and Continental Drift, involve theories about the oceans. As they are derived almost entirely from data obtained on land, the study of the other two thirds of the earth's surface may be expected to be illuminating.

\title{
BORON IN AGRICULTURAL AND HORTICULTURAL PRACTICE
}

$\mathrm{D}^{\mathrm{t}}$ URING the past year some three hundred and fifty papers and articles relating to the uses of boron compounds in agriculture and horticulture were published in twenty-one different countries. Nearly half of these contributions were made in the United States, where the rapidly growing interest in the subject was particularly marked. According to a recent report, boron investigations covering a wide range of soils and crops are now in progress in at least twenty-six American States. Important among the new findings published in the United States during the year was the efficacy of applications of boron to the soil in controlling canker disease, also termed girdle or internal black spot, of table or canning beet. The disorder appears to be closely related to heart rot, the wellknown boron deficiency disease of sugar beet and mangolds. Canker is said to be very prevalent and of considerable economic importance in the canning beet growing districts in the States of New York, Michigan, Oregon and Wisconsin. Its presence has also been observed in Washington State.

The beneficial use of boron on daffodils was reported from North Carolina, and further advance was made in New York State in the study of internal bark necrosis of apple trees and its control by the application of boron. A first progress report on drouth spot of prunes was also issued in the latter State. The first recorded instance of boron deficiency in cabbage and related crops, under field conditions, was reported from Wisconsin. The disorder, an internal breakdown of the stem in the region of the core, was largely controlled by the application of boron. In Florida, the condition of citrus trees in several groves is considered to suggest a lack of boron. An investigation of this possibility has been begun. An apparently new disorder of tomato plants, experienced in New Jersey, and characterized by a form of yellowing of the leaves, was controlled by suitable applications of boron. In the same State, the first recorded symptoms of boron deficiency in roses grown in sand cultures were described.

Three important reviews of literature were published in the United States during the year. The first supplement to the American Potash Institute's Bibliography of Literature "Boron as a Plant Nutrient" was issued in May and listed 171 papers reviewed during the period July to December, 1938. The Chilean Nitrate Educational Bureau Inc., New York, published the third edition of its well-known "Bibliography of References to Literature on the Minor Elements". This lists 449 papers relating to boron. A booklet entitled "Boron in Agriculture", published by the Pacific Coast Borax Company, New York, presents a concise and well-illustrated review of work conducted in the United States and Canada.

In New Zealand and Australia the list of crops which may suffer from boron deficiency under field. conditions was also extended. In the former country, workers at the Cawthron Institute found that a disorder of apricot fruits, which is sometimes prevalent in the orchards there, is due to lack of boron and can be controlled by the addition of boron to the soil or by spraying it on to the tree. The disorder in question has been termed 'brown spotting'. Further investigation of the subject is in progress. In Queensland, Australia, a condition of young pineapple plants, known as 'crookneck' (so called on account of the manner in which the heart leaves are twisted) was largely controlled by spraying the plants with boron. Progress was reported from New South Wales concerning the investigations being conducted there on needle fusion of pines. The application of boron to diseased trees has given complete or partial recovery in some cases, but in others has so far been without result. This disorder of pines also received further attention in Great Britain, where it was shown that the leaves of affected trees contained 
consistently less boron than did those of healthy trees. The results of additional investigations concerning the control of brown heart of swedes in New Zealand by the use of boron were reported. It was stated, too, that the use of boron for the control of cork disorders of apples in New Zealand is likely to have wide application in the Alexandra district of Central Otago.

Other notable contributions came from the Dutch East Indies and Hollanid. The symptoms of boron deficiency in coffee have been studied at the Besoeki Experiment Station in Java, and similar investigations on potatoes under both laboratory and field conditions were carried out in Holland. French workers extended their investigations to a study of the boron content of various types of soil, and have published their first results. Work in Canada related to swedes and turnips more particularly, and the use of boron there on additional crops is now being studied.

The Institute for Tobacco Research of the German Reich has investigated the essential nature of boron for the healthy growth of tobacco. As a result boron has been applied to its tobacco fields for some years, with good results. The well-known German worker, Brandenburg, published early in the year a review in German of available information concerning the use of boron in plant nutrition, with special reference to his own investigations. It was also reported from Germany that the production of borated superphosphate for use on the sugar beet crop in 1938 was 30,000 tons, compared with
20,000 tons in 1937. Another noteworthy feature was the publication by several workers in the United States, in Germany and in Great Britain of methods relating to the determination of boron in soils, plants and fertilizer materials.

Important developments, in addition to those already mentioned, took place in the British Isles. Further successful results relating to the control of brown heart in swedes and turnips by the use of boron were reported from Northern Ireland, the north-east of Scotland, and the north-west of England, in experiments carried out in 1938. These were the first investigations in the areas concerned. The disease was also reported to have been prevalent in Devon and Cornwall. In an experiment in Scotland in 1938, boron (applied as 'Boronite') gave a large measure of control of internal rust spot of potatoes.

Special mention must also be made of the publication early in the year, of the third of the reviews "Boron and Plant Life" (Fert. Feed. J., February-April, 1939.) This review, written by A. C. and R. W. G. Dennis, summarized developments reported in some two hundred papers during the latter half of 1937 and in 1938. The article was later published in French.

The foregoing is naturally only a brief outline of some of the more important items of information reported. It may serve, however, to indicate the wide range and extent of investigational work on boron now in progress and to record the more important advances recently made.

\title{
SOME EXPERIMENTS IN RABBIT CONTROL
}

\author{
By R. M. LOCKLEY, \\ SKoKholm ISLAND, PEMBROKEShIRE
}

\begin{abstract}
A TTEMPTS have been made over a period of twelve years to control and if possible exterminate the wild rabbit Oryctolagus cuniculus on the island of Skokholm, Pembrokeshire, so as to reserve pasture for other livestock.

Skokholm is composed almost entirely of Old Red Sandstone rising to an average height of $100 \mathrm{ft}$. above sea-level, is rock-bound, and often inaccessible in bad or moderate weather owing to its exposure to the strong Bristol Channel tides and the open Atlantic. The island was once a general farm (1800), but is now covered with rough grazings of rabbit-worn turf, heather, bracken and thrift. There are about 200 acres of rough grazings and some 42 acres of broken-up cliff ground and outcropping rock. So far back as $\mathbf{1 3 2 4}$ rabbits were marketed from the island
\end{abstract}

("Inquisition post mortem" of Aymer de Valence, Earl of Pembroke. 18 Edward II, No. 75), and later records show no break in the occupation of the island by rabbits up to the present day. This isolation in an exposed situation over centuries has produced a type weighing about four ounces less than the typical rabbit on the mainland of Pembrokeshire, from which the present-day Skokholm rabbit further differs in possessing a more plentiful admixture of black hairs on its upper parts.

The broken-down nature of the cliffs affords ideal refuge in the heaped-up boulders and talus, and makes control work difficult. While, owing to the use of all holes and burrows on the island by nesting sea-birds over a protracted breedingseason, treatment of burrows has to be confined to the three months November-January. 